7-15-2020

\title{
Commentary: Using law more effectively towards abandonment of FGM/C in Kenya
}

Agnes K. Meroka-Mutua

Follow this and additional works at: https://knowledgecommons.popcouncil.org/departments_sbsr-rh

Part of the Demography, Population, and Ecology Commons, Family, Life Course, and Society

Commons, Gender and Sexuality Commons, International Public Health Commons, and the Medicine and Health Commons

How does access to this work benefit you? Let us know!

\section{Recommended Citation}

Meroka-Mutua, Agnes K. 2020. "Commentary: Using law more effectively towards abandonment of FGM/ C in Kenya," Evidence to End FGM/C: Research to Help Women Thrive. New York: Population Council. 


\section{Using Law More Effectively Towards Abandonment of FGM/C in Kenya}

The Evidence to End FGM/C programme consortium generates evidence to inform and influence investments, policies, and programmes for ending female genital mutilation/ cutting in different contexts.

Population Council Lead Institution

Africa Coordinating Centre for the Abandonment of Female Genital

Mutilation/Cutting, Kenya (ACCAF)

Global Research and Advocacy Group, Senegal (GRAG)

MannionDaniels Ltd. (MD)

Population Reference

Bureau (PRB)

University of Washington (Prof. Bettina Shell-Duncan)

University of California, San Diego (Dr. Gerry Mackie)

\section{Funded by}

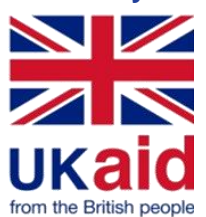

\section{Background and Context}

Female genital mutilation/cutting (FGM/C) is considered a harmful cultural practice and a form of violence against women because of the adverse effects it has on the physical and psychological well-being of women (WHO 2011). Kenya has an FGM/C prevalence rate of $21 \%$ (KDHS 2014), but levels vary by ethnic group. Out of 44 ethnic communities in Kenya, only four do not practise FGM/C-the Luo, Luhya, Turkana, and Teso. All other communities practise some type of FGM/C with prevalence varying with the Kisii at $84 \%$, the Samburu at $86 \%$, and the Somali at 94\% (KDHS 2014)

Kenya has adopted a robust legal framework for the prohibition of FGM/C. The Constitution guarantees the human rights of women and prohibits discrimination on the basis of gender. In addition, the Constitution ensures that regional and human rights instruments such as the Conventional on Elimination of all Forms of Discrimination Against Women (CEDAW) and the Additional Protocol to the African Charter on Human and Peoples' Rights on the Rights of Women in Africa (Maputo Protocol) form part of the law in Kenya and are directly applicable in the national context. Article 5(b) of the Maputo Protocol requires state parties to take legislative measures backed by sanctions, for the prohibition of all forms of $\mathrm{FGM} / \mathrm{C}$.
Against this backdrop, Kenya passed the Prohibition of FGM Act in 2011. This is the main statute that currently provides for the prohibition of FGM/C in Kenya, although other pieces of legislation, such as the Protection Against Domestic Violence Act, 2015 and the Children Act, 2001, contain provisions relating to $\mathrm{FGM} / \mathrm{C}$. The Prohibition of FGM Act is a detailed law that not only criminalises the carrying out of $\mathrm{FGM} / \mathrm{C}$, but also other associated offences, including: aiding and abetting procuring of $\mathrm{FGM} / \mathrm{C}$; the use of one's premises for FGM/C; being in possession of tools used for purposes of $\mathrm{FGM} / \mathrm{C}$; crossing the border to procure $\mathrm{FGM} / \mathrm{C}$ in another country; failing to report to authorities when one is aware that $\mathrm{FGM} / \mathrm{C}$ has been carried out; and the use of abusive or derogatory language to refer to a woman, or a man who marries a woman, who has not undergone FGM/C. The Act also provides for mandatory minimum sentences of three years imprisonment or a fine of Kshs. 200,000 $(\$ 2,000)$ for all offences under the Act.

Furthermore, when a victim of FGM/C dies, the Act imposes a mandatory sentence of life imprisonment. Kenya relies on the human rights-based approach and criminalisation in its legal framework for the prohibition of this practice. Despite these extensive legal provisions, Kenya has prosecuted fewer than 100 cases, raising concerns with the law's enforcement and implementation (28TooMany 2018; UNFPA-UNICEF 2016). 
This commentary reflects consultations with key actors in this space regarding the results of the Evidence to End FGMC Research Programme's study that assessed the role of law in reducing the practice in Kenya. Expert opinions on the implementation of Kenya's anti-FGM/C law and potential areas for strengthening of this approach have been collated to outline recommendations ${ }^{1}$ on how the legal framework for the prohibition of FGM/C in Kenya can be strengthened to better contribute towards abandonment of the practice. Representatives from the Office of the Chief Justice of the Republic of Kenya, the Office of the Director of Public Prosecutions, the Kenya Law Reform Commission, the Law Society of Kenya, UNICEF-Kenya, and the Anti-FGM Board contributed to the thinking outlined here. This commentary aims to inform the ongoing conversation on the effective use of legal frameworks for the elimination of FGM/C.

\section{What Does the Evidence Tell Us?}

Kenya's legal framework for the prohibition of $\mathrm{FGM} / \mathrm{C}$ uses penal sanctions as a deterrent measure. However, findings from the programme's research in Kenya found that criminalisation has a number of limitations including:

1. Criminalisation of $F G M / C$ conflicts with other semi-autonomous fields such as culture and religion. In order to avoid penal sanctions under the law, individuals find ways of circumventing the law. This means that fear of the law drives the practice further underground and individuals feel they cannot freely report incidents for fear that they, or others close to them, will face penal sanctions.

a. In some situations, the criminal prosecution of $\mathrm{FGM} / \mathrm{C}$ cases relies on the evidence of witnesses, who in many instances are bound by the cultural norms that promote the practice. Such witnesses consider it disloyal to their cultural practises to stand before a court of law to "betray" a brother or a sister from the community. b. Similarly, law enforcement officials are embedded in the community. The cultural, social, religious, and political aspects of the community affect them and impact how they handle $\mathrm{FGM} / \mathrm{C}$ cases because they also face the conflict of either staying true to their cultural and other social beliefs or enforcing the law. For example, some law enforcement officials sometimes choose not to pursue FGM/C-related cases because of the possible social consequences, especially considering the mandatory minimum sentences under the Prohibition of FGM Act. This was noted in one case where a single mother of three young children was sentenced to the mandatory three years leaving her children without parental protection.

2. Emphasis on criminalisation means that the prosecution of $\mathrm{FGM} / \mathrm{C}$ cases in Kenya focuses on technical and evidentiary issues of law. However, our desk review of court cases in Kenya found that FGM/C cases also raise human rights questions. For example:

a. In one case, the court did not define whether a school should expel girls who were found to have undergone FGM/C. In that case, the right to education was a pertinent issue.

b. In another case, where the accused persons were charged with aiding and abetting the commission of $\mathrm{FGM} / \mathrm{C}$ for voluntarily undergoing the practice, the issue of whether adult women can exercise the constitutional right to practice their culture by choosing to undergo $\mathrm{FGM} / \mathrm{C}$ was never raised.

c. Still in another case, the court did not address the issue of whether parents who failed to report their 16-year-old daughter who had undergone FGM/C voluntarily to the police were culpable of an offence or whether they simply act in the best interests of their daughter.

\footnotetext{
${ }^{1}$ This commentary provides a summary of recommendations discussed for consideration and does not reflect variations or levels in key actor agreements/disagreements to each, nor do the recommendations reflect the view of any one consortium partner.
} 
It is these types of human rights questions that have now given rise to a constitutional petition challenging the legality of the Prohibition of FGM Act. Courts play a vital law-making function, which is essential to developing the legal framework for the prohibition of $\mathrm{FGM} / \mathrm{C}$, and offering some direction as to how the human rights issues relating to $\mathrm{FGM} / \mathrm{C}$ cases should be addressed, while at the same time ensuring that the law continues to protect women from the human rights violations occasioned by FGM/C.

3. The general challenges affecting the criminal justice system in Kenya make it difficult for the Prohibition of FGM Act to be properly implemented and enforced. In rural FGM/C hotspots, for example Kipsing in Isiolo County and Emurua Dikiir in Narok County, there are few police and court stations, and law enforcement officers handling a case must travel long distances between police stations, scenes of crime, and courts. Witnesses are also forced to travel long distances to court stations and often lack the resources to do so, leading to a failure to attend court sessions as required. This affects the way in which investigations are conducted, how evidence is collected, and ultimately how prosecutions are carried out. Further, under circumstances where there are limited resources, other crimes that tend to be prevalent in rural FGM/C hotspots and which are considered more serious, such as cattle rustling and illegal brewing of traditional alcohol, will routinely receive more attention from law enforcement officials as opposed to FGM/C.

\section{Current policy direction on the use of criminal law to change behaviour}

Policy direction on the use of criminal law to change behaviour often calls for stricter application of the law and harsher penalties in situations where the law is not achieving the desired deterrent effects. Yet, findings from the programme's study show that criminalisation of the practice might not be a strong deterrent. Instead, FGM/C is being pushed into secrecy to avoid penal sanctions. Data from the programme's work on the role of law in reducing $\mathrm{FGM} / \mathrm{C}$ and on shifting norms and practices among communities in Kenya show that FGM/C is being practised on younger girls who have not started attending school, on adult women who are already married, or across the territorial boundaries of border communities.

$\mathrm{FGM} / \mathrm{C}$ is rooted in culture and for individuals to abandon the practice cultural norms that inform it must first be transformed. This points to a need to shift from approaches that call for the use of harsher penal sanctions and instead apply legislation in innovative ways that are likely to promote the cultural transformation needed for abandonment of the practice.

\section{Key Actor Recommendations for Using Law More Effectively Towards the Abandonment of FGM/C}

\section{Reforming the Law}

As the society relies on law to protect women and girls from $\mathrm{FGM} / \mathrm{C}$, other rights, such as the right to education for girls who have undergone $F G M / C$, should also be respected and protected. In addition to the already-existing criminal provisions that prohibit FGM/C, legal provisions that specify the role and functions of other key actors such as cultural and religious leaders, healthcare workers, and education institutions should be adopted.

Kenya has many other laws which are regulatory in nature, for instance, laws on education, labour, and health. These laws hardly create criminal offences, but instead, focus on strengthening the work of those involved in these sectors, by providing clarity on their roles, establishing obligations as to how their functions are to be discharged, as well as providing for budgetary allocation. The prohibition of $\mathrm{FGM} / \mathrm{C}$ is likely to be more effective if it mirrors these regulatory provisions to complement the criminalisation aspects of the law. Such legal provisions are likely to strengthen community-based interventions aimed at ending FGM/C and they are also less likely to be perceived as an attack on the cultures of practising communities.

FGM/C as currently defined under the law in Kenya mirrors the WHO definition, which is the partial or total removal of the external genitalia or other injury to the female genital organs for nonmedical reasons (WHO 2011). However, for 
some practising communities, FGM/C is part of a cultural rite of passage that includes the induction of girls into womanhood and the informal education girls receive from older women. Many in practising communities wrongly understand the prohibition of $F G M / C$ to mean that all actions associated with the practice are prohibited, whereas in fact, it is only the cutting of genitalia that is prohibited. This misunderstanding results in low acceptance of the law and low levels of compliance. Hence it is important to provide a holistic definition of the practice and to then single out the specific aspects that are prohibited.

Changing trends in the practice, such as medicalisation (FGM/C performed by healthcare professionals), should also be reflected in the law. While the Prohibition of FGM Act provides a broad definition of $F G M / C$ that could potentially cover medicalised FGM/C, the failure to define what medicalised $\mathrm{FGM} / \mathrm{C}$ is under the law as well as to expressly provide for it as a special offence creates a lacuna in the criminalisation of FGM/C.

Finally, there is a need to address the impact of the general weaknesses of Kenya's criminal justice system on the prosecution of FGM/C cases. This can be done by strengthening collection of evidence, witness protection, and the prioritisation of $\mathrm{FGM} / \mathrm{C}$ cases in court that can be used during prosecutions.

\section{Strengthening Criminal Prosecution of FGM/C Related Cases}

Where criminal prosecution is required, this can be strengthened by having an FGM/C desk in police stations in hotspot areas, or alternatively, building the capacity of the gender desk to handle FGM/C cases. This desk should work closely with the FGM/C unit in the Office of the Director of Public Prosecutions (ODPP). Further, an evidence-collection kit, similar to the rape kit used in sexual offences, could be developed to allow for more effective collection and storage of evidence. This would enable systematic documentation of the type of cut and other injuries suffered by the victim. Witnesses in FGM/C-related cases need to be assured that they will be protected from backlash from the community.

\section{Recommendations to the Law Reform}

Commission: The Prohibition of FGM Act should be amended to include a section that sets out the role and functions of cultural and religious leaders, healthcare workers, and education institutions in the fight against FGM/C. The content of the amendment to the Prohibition of FGM Act on the role of healthcare workers, education institutions, and cultural and religious leaders in curbing FGM/C should be developed consultatively with stakeholders in these sectors.

The Prohibition of FGM Act should be amended to remove the mandatory minimum sentences. Judicial officers should be allowed discretion when it comes to sentencing, as the mandatory sentences can sometimes be oppressive, and this causes practicing communities to lack confidence in the law and the legal system.

The Prohibition of FGM Act should be amended to include a legal definition of medicalised FGM/C and a special offence criminalising medicalised FGM/C should be expressly provided for. In addition, the definition of $F G M / C$ should consider cultural perspectives of what FGM/C entails. With this, the law should specify which part of the practice is prohibited and criminalised.

The sections of the Prohibition of FGM Act which create offences should be revised and reviewed to address the challenges posed by the conflict between law and culture. The creation of offences under the Prohibition of FGM Act should be done in a manner that considers the post-prosecution and conviction effects on the family unit in particular.

- Recommendation to the ODPP and Kenya Police: The ODPP and the Kenya Police should together establish a taskforce to determine whether an FGM/C Desk should be set up or in the alternative the capacity of the Gender Desk should be developed to support FGM/C cases. The taskforce should also advise on the development and rolling out of an FGM/C evidence kit.

- Recommendation to ODPP: The ODPP should explore how witnesses in FGM/C cases can be put into witness protection. 
- Recommendation to the Judiciary: Mobile courts in FGM/C hotspots should be set up to help address the prosecution of cases in areas with limited infrastructure. Court users' committees should also enable the prioritisation of $\mathrm{FGM} / \mathrm{C}$ cases so that they are not neglected in favour of other types of cases.

\section{Developing FGM/C Jurisprudence}

It is necessary for the courts to begin to address the conflict and competition that arises between different sets of rights when determining cases on FGM/C. This will provide much-needed direction on how other decisionmakers should address the conflict between the FGM/C law on the one hand and culture and religion on the other hand. The development of FGM/C jurisprudence is also essential in informing cultural transformation towards abandonment of the practise. This may require a shift in thinking of the judicial officers and a robust training on some of the critical social aspects of $F G M / C$ in the communities where they work.

- Recommendation to the Judiciary: The Judiciary should develop guidelines on appropriate options to be taken in FGM/C issues. These may include the kind of orders to be given, for example, custodial, noncustodial, probation, or community service. Further, the Judicial Training Institute should offer training to judicial officers on the social consequences of FGM/C and how these impact the law.

- Recommendation to the Law Society of Kenya: The Law Society of Kenya should offer training to advocates on the social consequences of $\mathrm{FGM} / \mathrm{C}$ and the human rights issues that arise out of the criminal prosecution of $\mathrm{FGM} / \mathrm{C}$ cases, in order to build the capacity of lawyers who litigate FGM/C cases before the courts. The Law Society of Kenya should also issue a statement on the role of lawyers in the fight against $\mathrm{FGM} / \mathrm{C}$.

\section{Community Engagement}

Creation of public awareness about the law should avoid the approach that focuses on instilling fear of punishment under the law, as this erodes confidence in the law. Instead, it is necessary to work with cultural, religious, and community leaders in developing messages that will instil confidence in the law. These include leaders at the grassroots level, working with other stakeholders, such as the Anti-FGM Board, in creating public awareness about FGM/C and the law. In particular, law should be promoted as a means through which all human rights are protected, respected, guaranteed, and furthered. This can promote acceptance of the law at the community level, and in turn, this would instil confidence in the legal system. At the moment, it is more the fear of the law rather than the respect for it that drives communities.

- Recommendations to the Anti-FGM Board: The Anti-FGM Board should work closely with cultural, religious, community and political leaders, and relevant NGOs and CBOs in the grassroots to develop positive messaging about the law. This messaging should focus on instilling public confidence in the law rather than instilling fear of the law.

In collaboration with the line ministries and other stakeholders in the education and legal sectors, the Anti-FGM Board should lead the process of developing a curriculum for use in schools, both for basic education and high school, which provides key human rights information about FGM/C. This will empower children to know and understand what their human rights are in the context of $\mathrm{FGM} / \mathrm{C}$, and where and how to seek help in case of any FGM/C-related threats. It is also likely to promote generational change, so that when the children grow up, they can make the choice not to cut their daughters. 


\section{References}

28TooMany. 2018. "Kenya: The Law and FGM." Thompson Reuters Foundation. 2018. Available at https://www.28toomany.org/country/kenya

Kenya Law. 2014. Agnes Wanjiru Kiraithe \& another $v$ Attorney General \& 2 others. Nairobi: Kenya High Court, eKLR.

Kenya Law. 2015. S M G v R A M. Nairobi: Kenya High Court, eKLR.

Kenya Law. 2016. Jessica Magerer v Republic. Nairobi: Kenya High Court, eKLR.

Kenya Law. 2019. Charity Karimi \& 2 others v Republic. Nairobi: Kenya High Court, eKLR.

National Bureau of Statistics-Kenya (KNBS) and ICF International. 2015. 2014 KDHS Key Findings. Rockville, MD: KNBS and ICF International.

Matanda, D., C. Okondo, C. Kabiru, and B. ShellDuncan. 2018. "Tracing Change in Female Genital Mutilation/Cutting: Shifting Norms and Practices Among Communities in Narok and Kisii Counties, Kenya." Evidence to End FGM/C: Research to Help Women Thrive. New York: Population Council.

Meroka-Mutua, A., D. Mwanga, O.C. Olungah. 2020.

"Assessing When and How Law Is Effective in Reducing the Practise of FGM/C in Kenya." Evidence to End FGM/C: Research to Help Girls and Women Thrive. New York: Population Council.

Shell-Duncan, B., D. Gathara,Z. Moore. 2017. "Female Genital Mutilation/Cutting in Kenya: Is Change Taking Place? Descriptive Statistics from Four Waves of Demographic and Health Surveys." Evidence to End FGM/C: Research to Help Girls and Women Thrive. New York: Population Council.

UNFPA-UNICEF Joint Programme. 2016. Annual Report of the UNFPA-UNICEF Joint Programme on Female Genital Mutilation/Cutting: Accelerating Change. New York: UNFPA-UNICEF.

World Health Organization (WHO). 2011. An Update on WHO's Work on Female Genital Mutilation: Progress Report. Geneva: WHO. Available at: https://apps.who.int/iris/bitstream/handle/10665/70638/W HO RHR 11.18 eng.pdf;jsessionid=C53CBE6442F61B BA038F56365E6E6B6A? sequence $=1 ; 2011$.
Citation: Meroka-Mutua, A. 2020. Commentary: Using Law More Effectively Towards Abandonment of FGM/C in Kenya. Evidence to End FGM/C: Research to Help Women Thrive. New York: Population Council. 